\title{
Sex-specific longitudinal association of DNA methylation with lung function
}

\author{
Shadia Khan Sunny $\mathbb{B}^{1}$, Hongmei Zhang $\mathbb{B}^{1}$, Caroline L. Relton ${ }^{2}$, Susan Ring ${ }^{2,3}$, Latha Kadalayil ${ }^{4}$, \\ Fawaz Mzayek ${ }^{1}$, Susan Ewart ${ }^{5}$, John W. Holloway $\mathbb{C}^{4,6}$ and S. Hasan Arshad ${ }^{6,7,8}$
}

${ }^{1}$ Division of Epidemiology, Biostatistics, and Environmental Health, School of Public Health, University of Memphis, Memphis, TN, USA. ${ }^{2}$ MRC Integrative Epidemiology Unit, University of Bristol, Bristol, UK. ${ }^{3}$ Population Health Sciences, University of Bristol, Bristol, UK. ${ }^{4}$ Human Development and Health, Faculty of Medicine, University of Southampton, Southampton, UK. ${ }^{5}$ Large Animal Clinical Sciences, Michigan State University, East Lansing, MI, USA. ${ }^{6}$ NIHR Southampton Biomedical Research Centre, University Hospital Southampton, Southampton, UK. ${ }^{7}$ Clinical and Experimental Sciences, Faculty of Medicine, University of Southampton, Southampton, UK. ${ }^{8}$ The David Hide Asthma and Allergy Research Centre, St Mary's Hospital, Isle of Wight, UK.

Corresponding author: Hongmei Zhang (hzhang6@memphis.edu)

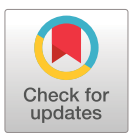

Copyright @The authors 2021

This version is distributed under the terms of the Creative Commons Attribution Non-Commercial Licence 4.0. For commercial reproduction rights and permissions contact permissions@ersnet.org

This article has supplementary material available from openres.ersjournals.com

Received: 23 Feb 2021 Accepted: 16 April 2021

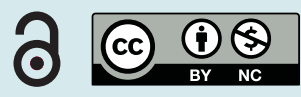

Shareable abstract (@ERSpublications)

Population-based cohort studies show that methylated sites at an earlier age are associated with lung function at a later age, possibly sex-specifically, and detected markers could serve as candidates on lung function deficit prediction in future studies https://bit.ly/3av22Dx

Cite this article as: Sunny SK, Zhang H, Relton CL, et al. Sex-specific longitudinal association of DNA methylation with lung function. ERJ Open Res 2021; 7: 00127-2021 [DOI: 10.1183/23120541.001272021].

\section{Abstract}

Investigating whether DNA methylation (DNA-M) at an earlier age is associated with lung function at a later age and whether this relationship differs by sex could enable prediction of future lung function deficit.

A training/testing-based technique was used to screen 402714 cytosine-phosphate-guanine dinucleotide sites (CpGs) to assess the longitudinal association of blood-based DNA-M at ages 10 and 18 years with lung function at 18 and 26 years, respectively, in the Isle of Wight birth cohort (IOWBC). Multivariable linear mixed models were applied to the CpGs that passed screening. To detect differentially methylated regions (DMRs), DMR enrichment analysis was conducted. Findings were further examined in the Avon Longitudinal Study of Parents and Children (ALSPAC). Biological relevance of the identified CpGs was assessed using gene expression data.

DNA-M at eight CpGs (five CpGs with forced expiratory volume in $1 \mathrm{~s}\left(\mathrm{FEV}_{1}\right)$ and three CpGs with $\mathrm{FEV}_{1} /$ forced vital capacity (FVC)) at an earlier age was associated with lung function at a later age regardless of sex, while at $13 \mathrm{CpGs}$ (five CpGs with FVC, three with $\mathrm{FEV}_{1}$ and five with $\mathrm{FEV}_{1} / \mathrm{FVC}$ ), the associations were sexspecific $\left(\mathrm{p}_{F D R}<0.05\right)$ in IOWBC, with consistent directions of association in ALSPAC (IOWBC-ALSPAC consistent CpGs). cg16582803 (WNT10A) and cg14083603 (ZGPAT) were replicated in ALSPAC for main and sex-specific effects, respectively. Among IOWBC-ALSPAC consistent CpGs, DNA-M at cg01376079 (SSH3) and cg07557690 (TGFBR3) was associated with gene expression both longitudinally and cross-sectionally. In total, 57 and 170 DMRs were linked to lung function longitudinally in males and females, respectively.

CpGs showing longitudinal associations with lung function have the potential to serve as candidate markers in future studies on lung function deficit prediction.

\section{Introduction}

Lung function is pivotal for the diagnosis of respiratory diseases and predicts future disease development [1]. Lung function, specifically forced expiratory volume in $1 \mathrm{~s}\left(\mathrm{FEV}_{1}\right)$, is inversely correlated with morbidities such as asthma and COPD, and early mortality [2, 3]. The growth of lung function in childhood and adolescence is associated with age and height and the decline in adulthood is related to ageing [3, 4]. In addition, the maximal level of lung function and the age of decline are dependent on sex [3, 5]. Several biological factors determine such sex-dependency including anatomical, immunological, and hormonal factors $[5,6]$. 
The impact of environmental factors on respiratory health and lung function is significant [7]. The importance of the interaction between genetic and environmental factors in determining lung function suggests that other gene regulatory processes [8], such as epigenetic mechanisms, may act as an interface between environmental exposures and genetics [9, 10]. DNA methylation (DNA-M), most commonly the addition of a methyl group onto the $5^{\prime}$ position of the cytosine base at cytosine-phosphate-guanine dinucleotide sites (CpGs), regulates gene expression by recruiting proteins involved in gene repression or by impeding the binding of transcriptional proteins to DNA [11]. Several studies have shown the association of blood-based DNA-M with lung function [12-17] or with related diseases such as asthma [18] and COPD [12-15]. Most existing epigenetic studies on lung function were cross-sectional and focused on older people (>40 years) [12-16]. Cross-sectional designs are subject to reverse causation and create temporal ambiguity. To our knowledge, no existing studies have used repeated measurements of DNA-M, together with longitudinally measured lung function to assess the association of DNA-M with lung function and the stability of these associations over time.

DNA-M changes over time at specific CpGs [19, 20], and such changes have been shown to be sex-specific [20, 21]. Changes in DNA-M can occur in response to biological ageing, but also to environmental exposures [22]. That is, DNA-M at certain CpGs reflects the memory of past exposure as well as significant changes at different stages of life. The association between change in DNA-M and change in lung function has been shown to be different between males and females [23]. However, it is unknown whether DNA-M at an earlier age is associated with lung function at a later age, whether such longitudinal associations are invariant to DNA-M changes over time, and how such associations are different between males and females. A longitudinal design with repeatedly measured DNA-M and lung function data would allow assessment of the stability of time-lagged associations between DNA-M and lung function. As DNA-M has been found to be a potential driver of biological ageing [24], DNA-M biomarkers which have a stable time-lagged association could be useful to predict lung function deficit and detect possible related diseases at an earlier age before the pathology becomes apparent. We hypothesised that DNA-M at specific CpGs in early life is associated with lung function at a later age and such association would be sex-specific. The study was carried out in the Isle of Wight birth cohort (IOWBC) in the UK. To assess generalisability, the findings were further examined in an independent birth cohort, the Avon Longitudinal Study of Parents and Children (ALSPAC) cohort in the UK.

\section{Materials and methods \\ Study subjects and design \\ IOWBC: discovery cohort}

IOWBC is a prospective population-based birth cohort established in 1989. Longitudinal monitoring of allergic diseases, phenotypic measures, genetics and assessments of environmental exposures were conducted at birth and multiple ages from 1 year to 26 years of age. Forced vital capacity (FVC) and FEV 1 were measured at age 10 years $(n=980), 18$ years $(n=838)$ and 26 years $(n=546)$, and the ratio of $F_{1}$ over FVC $\left(\mathrm{FEV}_{1} / \mathrm{FVC}\right)$ was calculated. Genome-wide DNA-M was measured from peripheral blood samples collected at age 10 years $(n=330), 18$ years $(n=476)$ and 26 years $(n=303)$ from randomly selected subjects for whom DNA was available using the Infinium HumanMethylation450K or EPIC BeadChips (Illumina, Inc., San Diego, CA, USA). After quality control, preprocessing, and excluding probes with single nucleotide polymorphisms, 402714 CpGs were included in the statistical analyses. RNA-sequencing gene expression data for subjects at age 26 years was available in IOWBC. A detailed description of IOWBC can be found in the online supplement.

\section{ALSPAC: replication cohort}

Findings in the IOWBC were further tested in an independent cohort, ALSPAC [25, 26], where DNA-M data at age 7 and 15 years and lung function measurements at age 15 and 24 years were available for replication analyses. Details of these data along with information on covariates are presented in the online supplement. The study website contains details of all the data that is available through a fully searchable data dictionary and variable search tool (http://www.bristol.ac.uk/alspac/ researchers/our-data/).

\section{Statistical analyses}

To assess whether subjects examined in the study at ages 18 and 26 years reasonably represented those in the complete IOWBC, continuous variables were evaluated using nonparametric one sample sign tests and categorical variables were examined implementing one-sample proportion tests. 


\section{Analyses of longitudinal association}

Lung function measurements at each age were adjusted by height. DNA-M adjusted for cell types, principle components, and batch effects at each $\mathrm{CpG}$ was used (see details in the online supplement). In IOWBC, a two-step analytical approach was used to assess the longitudinal association between DNA-M and lung function at two time-lagged periods: period-1 (10-18 years), the association of DNA-M at age 10 years with lung function at 18 years; and period-2 (18-26 years), the association of DNA-M at age 18 years with lung function at 26 years. In the first step, we filtered out CpGs not potentially associated with lung function in either of the two periods using a screening package, "ttScreening" in $\mathrm{R}$ 3.3.2 version (detailed in the online supplement) [27, 28]. The screening was applied to each lung function parameter and performed for both time periods, stratified by sex.

In the second step, linear mixed models (LMM) with repeated measures were implemented in period- 1 and period-2 in SAS 9.4 (SAS Institute Inc., Cary, NC, USA). Model-1 focused on the main effects of DNA-M. Potential confounders, including birth weight, gestational age, sex, duration of breastfeeding, maternal smoking exposure during pregnancy, recurrent chest infection at ages 1,2 and 4 years, socioeconomic status, repeated measures of body mass index, smoking status, and paracetamol use at ages 18 and 26 years, were included in model-1. To assess sex-specificity, we further extended model-1 by including DNA-M $\times$ sex interaction in model-2. Multiple testing was corrected by controlling false discovery rate (FDR) of 0.05 in both models [29].

\section{Analyses of differentially methylated regions (DMRS)}

Regional differential methylation signals among the CpGs that passed screening were examined using DMRcate [30] with default settings of including $\geqslant 2$ significant CpGs that passed screening in a region of $\geqslant 1000$ nucleotides $\left(\mathrm{p}_{F D R}<0.05\right)$ [30] (detailed in the online supplement).

\section{Replication analysis in ALSPAC}

The CpGs identified in IOWBC were further examined in ALSPAC to validate the IOWBC findings. Following a similar approach as that in the IOWBC, i.e. via LMMs with repeated measures, the

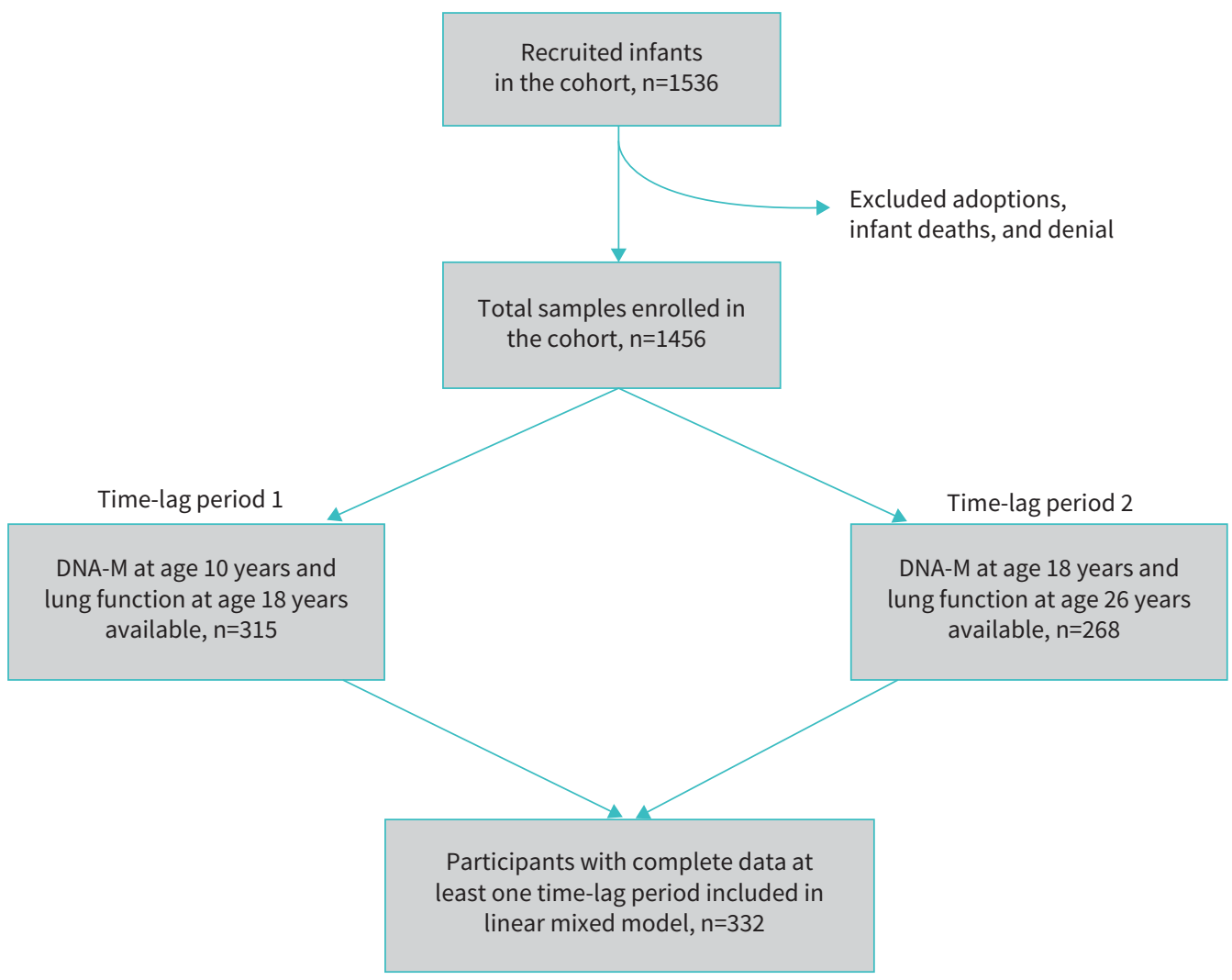

FIGURE 1 Flow chart for final sample determination in the Isle of Wight birth cohort. DNA-M: DNA methylation. 


\begin{tabular}{|c|c|c|c|}
\hline Variables & Analytical sample & Enrolled sample & $\mathrm{p}$-value \\
\hline Age 18 years & $n=315$ & $n=839$ & \\
\hline \multicolumn{4}{|l|}{ Lung function } \\
\hline FVC (L) & $4.62(4.04,5.52)$ & $4.47(3.93,5.32)$ & 0.071 \\
\hline $\mathrm{FEV}_{1}(\mathrm{~L})$ & $4.11(3.55,4.74)$ & $3.91(3.44,4.51)$ & 0.0067 \\
\hline $\mathrm{FEV}_{1} / \mathrm{FVC}$ & $0.88(0.82,0.93)$ & $0.88(0.83,0.92)$ & 0.37 \\
\hline Height $(\mathrm{cm})$ & $172.5(164,178.5)$ & $171(164,178)$ & 0.36 \\
\hline BMI $\left(\mathrm{kg} \cdot \mathrm{m}^{-2}\right)$ & $22.36(20.32,24.84)$ & $22.15(20.27,24.81)$ & 0.40 \\
\hline \multicolumn{4}{|l|}{ Sex } \\
\hline Male & $181(57.46)$ & $396(47.20)$ & 0.0019 \\
\hline Female & $134(42.54)$ & $443(52.80)$ & \\
\hline \multicolumn{4}{|l|}{ Smoking } \\
\hline Non-smoker & $167(53.02)$ & $462(55.07)$ & 0.90 \\
\hline Current smoker & $80(25.40)$ & $205(24.43)$ & \\
\hline Past smoker & $64(20.32)$ & $159(18.95)$ & \\
\hline Missing & $4(1.27)$ & $13(1.55)$ & \\
\hline Age 26 years & $n=268$ & $\mathrm{n}=547$ & \\
\hline \multicolumn{4}{|l|}{ Lung function } \\
\hline FVC (L) & $4.66(4.13,5.57)$ & $4.72(4.14,5.69)$ & 0.76 \\
\hline $\mathrm{FEV}_{1}(\mathrm{~L})$ & $3.70(3.33,4.49)$ & $3.76(3.33,4.55)$ & 0.18 \\
\hline $\mathrm{FEV}_{1} / \mathrm{FVC}$ & $0.81(0.77,0.84)$ & $0.81(0.77,0.85)$ & 0.81 \\
\hline Height $(\mathrm{cm})$ & $170(164.45,178)$ & $171(164.4,178.0)$ & 0.17 \\
\hline BMI $\left(\mathrm{kg} \cdot \mathrm{m}^{-2}\right)$ & $25.1(22.30,29.05)$ & $24.80(22.0,28.8)$ & 0.54 \\
\hline \multicolumn{4}{|l|}{ Sex } \\
\hline Male & $105(39.18)$ & $236(43.14)$ & 0.28 \\
\hline Female & $163(60.82)$ & $311(56.86)$ & \\
\hline \multicolumn{4}{|l|}{ Smoking } \\
\hline Non-smoker & $145(54.10)$ & $288(52.65)$ & 0.021 \\
\hline Current smoker & $61(22.76)$ & $128(23.40)$ & \\
\hline Past smoker & $59(22.01)$ & $101(18.46)$ & \\
\hline Missing & $3(1.12)$ & $30(5.48)$ & \\
\hline
\end{tabular}

longitudinal association of DNA-M at age 7 years with lung function at age 15 years, and DNA-M at age 15 years with lung function at age 24 years was examined, controlling the effects of confounders except for two covariates, recurrent chest infection and paracetamol use, which were unavailable.

\section{Gene expression analysis}

To assess potential biological relevance of the identified CpGs in model-1 and -2, we examined the association of DNA-M at those CpGs with the expression of their corresponding genes in blood. Linear regressions were applied to two datasets, DNA-M at age 18 years with gene expression at 26 years (longitudinal associations) and DNA-M at age 26 years with gene expression at the same age (cross-sectional associations).

\section{Results}

Results of longitudinal association analysis in IOWBC

In total, 332 (172 females) participants were included who had the complete (both DNA-M and lung function) data in at least one of the two periods (figure 1). The analysed sub-samples at age $18(\mathrm{n}=315)$ and 26 years $(n=268)$ were not statistically different from the enrolled sample with lung function (18 years, $\mathrm{n}=839 ; 26$ years, $\mathrm{n}=547$ ) for $\mathrm{FVC}, \mathrm{FEV}_{1}$, and $\mathrm{FEV}_{1} / \mathrm{FVC}$ at the corresponding ages, except $\mathrm{FEV}_{1}$ at age 18 years which was higher in the subsample (table 1). Using ttScreening, in total, 194, 207, and 149 CpGs with DNA-M at ages 10 and 18 years were identified as associated with FVC, FEV 1 , and $\mathrm{FEV}_{1} / \mathrm{FVC}$ at 18 and 26 years, respectively. These CpGs were then included in subsequent analyses (figure 2). In

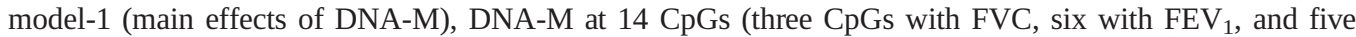
with $\left.\mathrm{FEV}_{1} / \mathrm{FVC}\right)$ at earlier ages was associated with lung function at later ages longitudinally $\left(\mathrm{p}_{F D R}<0.05\right.$, table S1) after adjusting the confounders. In model-2 (interaction effects of DNA-M×sex), DNA-M at 26 


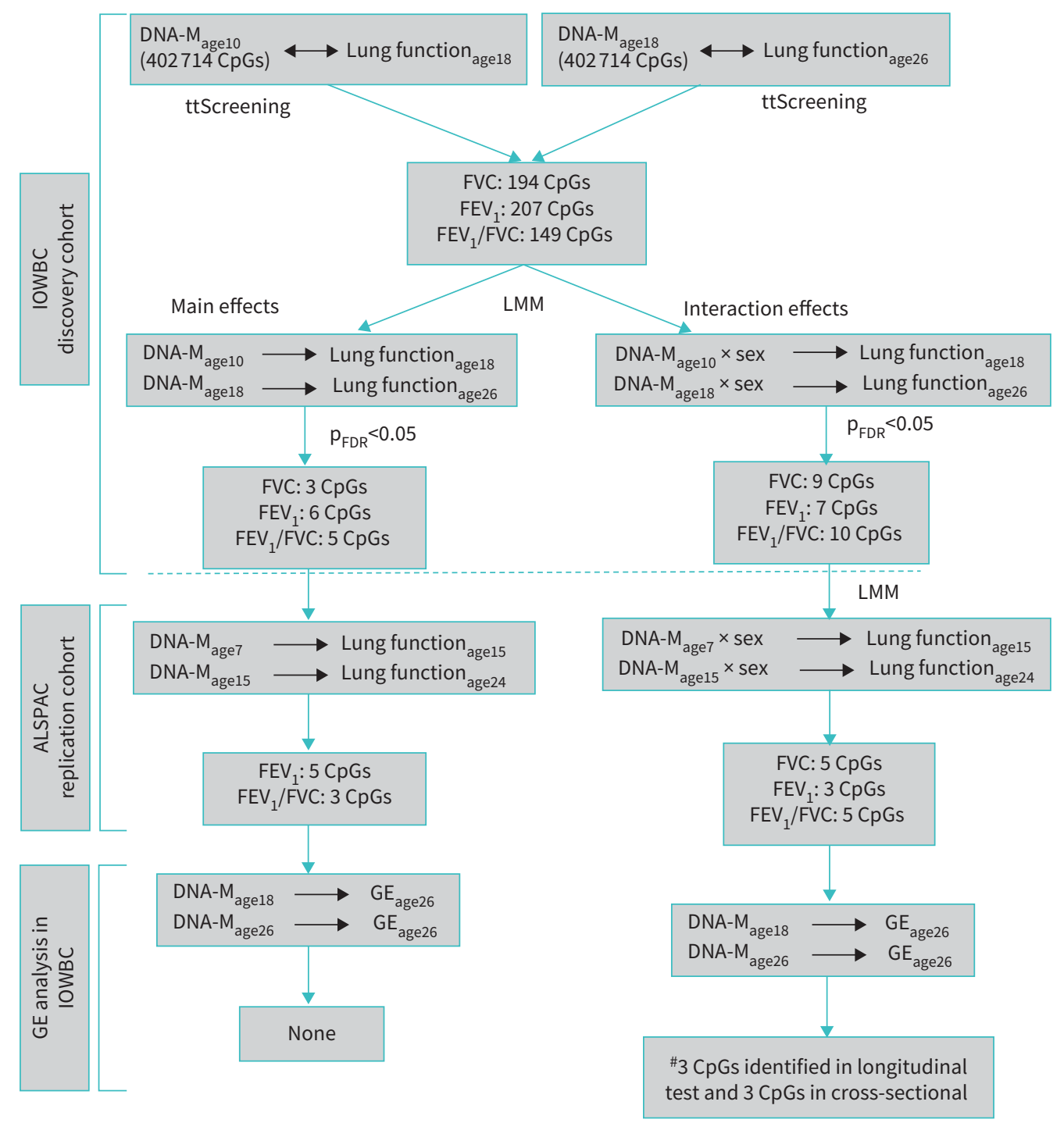

FIGURE 2 Flow chart of statistical analyses and the number of cytosine-phosphate-guanine dinucleotide sites (CpGs) after each step. IOWBC: Isle of Wight birth cohort; ALSPAC: Avon Longitudinal Study of Parents and Children; GE: gene expression; DNA-M: DNA methylation; DNA-M $\mathrm{agex}_{\mathrm{X}}$ DNA-M at age $\mathrm{X}$ years; Lung function $_{\text {agex: }}$ lung function at age $\mathrm{X}$ years; $\mathrm{GE}_{\text {age26: }}$ gene expression at age 26 years; FDR: false discovery rate; FVC: forced vital capacity; FEV ${ }_{1}$ : forced expiratory volume in $1 \mathrm{~s}$; LMM: linear mixed models. ": 2 CpGs are common between the longitudinal and cross-sectional analysis of DNA-M with GE.

CpGs showed sex-specific associations with lung function (nine CpGs with FVC, seven with $\mathrm{FEV}_{1}$, and 10 with $\mathrm{FEV}_{1} / \mathrm{FVC} ; \mathrm{p}_{F D R}<0.05$ ) (table S2, figure 2). The cg14083603 in WNT10A was identified by both model-1 and model-2.

\section{Replication in ALSPAC cohort}

In total, 1342 participants (610 males) in ALSPAC had complete data (DNA-M and lung function) in at least one period. Among the $14 \mathrm{CpG}$ identified in model-1 in IOWBC, five for $\mathrm{FEV}_{1}$ and three for $\mathrm{FEV}_{1} /$ FVC showed consistent directions of associations for the main effects, of which the effect of cg16582803 (WNT10A) was statistically significant $(\mathrm{p}=0.034)$ for $\mathrm{FEV}_{1}$ (table 2). Among the IOWBC-ALSPAC consistent eight CpGs, higher DNA-M at five CpGs (three associated with $\mathrm{FEV}_{1}$ and two with $\mathrm{FEV}_{1}$ / FVC), mapped to ANKRD9, WNT10A, ZNF727, NRN1, and DNAJB6, at earlier ages were associated with lower lung function at later ages. While at the remaining three CpGs, mapped to HINFP, EFNA2 and C16orf87, higher DNA-M at earlier ages was associated with higher lung function at later ages (table 2). In model 2, 13 of the $26 \mathrm{CpGs}$ (five CpGs associated with FVC, three with $\mathrm{FEV}_{1}$, and five with $\mathrm{FEV}_{1}$ / 
TABLE 2 DNA methylation at cytosine-phosphate-guanine dinucleotide sites (CpGs) at earlier ages that showed consistent direction of associations with lung function at later age between the Isle of Wight birth cohort (IOWBC) and the Avon Longitudinal Study of Parents and Children (ALSPAC)

\begin{tabular}{|c|c|c|c|c|c|c|c|c|c|}
\hline \multirow[t]{2}{*}{ Lung function measure } & \multirow[t]{2}{*}{ CpGs } & \multirow[t]{2}{*}{ Chromosome number } & \multirow[t]{2}{*}{ Gene } & \multirow[t]{2}{*}{ Location ${ }^{\#}$} & \multicolumn{3}{|c|}{ IOWBC } & \multicolumn{2}{|c|}{ ALSPAC } \\
\hline & & & & & Coefficient & $\mathrm{p}_{\text {RAW }}$ & $\mathrm{p}_{F D R}$ & Coefficient & p-value \\
\hline \multicolumn{10}{|l|}{$\mathrm{FEV}_{1}$} \\
\hline & $\operatorname{cg} 10729557$ & 14 & ANKRD9 & Intergenic & -0.18 & 0.0008 & 0.035 & -2.02 & 0.22 \\
\hline & cg16582803 & 2 & WNT10A & Intergenic & -0.16 & 0.0002 & 0.028 & -0.59 & 0.034 \\
\hline & cg17315331 & 11 & HINFP & TSS200 & 0.06 & 0.0003 & 0.028 & 1.60 & 0.84 \\
\hline & cg26174454 & 19 & EFNA2 & Intergenic & 0.23 & 0.0007 & 0.035 & 0.44 & 0.15 \\
\hline & cg27599129 & 7 & ZNF727 & Intergenic & -0.23 & 0.001 & 0.035 & -0.06 & 0.86 \\
\hline \multicolumn{10}{|l|}{$\mathrm{FEV}_{1} / \mathrm{FVC}$} \\
\hline & $\operatorname{cg} 18760835$ & 6 & NRN1 & Intergenic & -0.01 & 0.0004 & 0.041 & -0.22 & 0.33 \\
\hline & cg21240861 & 7 & DNAJB6 & TSS200 & -0.004 & 0.0014 & 0.041 & -0.05 & 0.95 \\
\hline & $\operatorname{cg} 27601198$ & 16 & C16orf87 & Intergenic & 0.01 & 0.0011 & 0.041 & 0.08 & 0.28 \\
\hline $\begin{array}{l}\text { Coefficients of IOWBC-AL } \\
\text { showed the same direct } \\
\text { forced vital capacity; } \\
\text { testing adjustment. ": ge } \\
\text { SNIPPER. }\end{array}$ & $\begin{array}{l}\text { AC consisten } \\
\text { of associati } \\
\text { : p-value } \\
\text { located at i }\end{array}$ & $\begin{array}{l}\text { Gs for the associatio } \\
\text { and were significan } \\
r \text { multiple testing } \\
\text { rgenic locations were }\end{array}$ & $\begin{array}{l}\text { DNA m } \\
0.05 \text { le } \\
\text { ection } \\
t \text { found }\end{array}$ & $\begin{array}{l}\text { lation at } \\
\text { re shown } \\
\text { controllin }\end{array}$ & $\begin{array}{l}\text { er age wit } \\
\text { bold font. } \\
\text { Ise disco } \\
\text { notation } f\end{array}$ & $\begin{array}{l}\text { ung fur } \\
=\mathrm{V}_{1} \text { : for } \\
y \text { rate; } \\
\text { and } w\end{array}$ & $\begin{array}{l}\text { n at } \\
\text { expi } \\
\text { Aw: }\end{array}$ & $\begin{array}{l}\text { er age. Th } \\
\text { y volume } \\
\text { lue witho } \\
\text { using the }\end{array}$ & $\begin{array}{l}\text { CpGs that } \\
1 \mathrm{~s} ; \mathrm{FVC} \\
\text { multiple } \\
\text { line too }\end{array}$ \\
\hline
\end{tabular}

FVC) showed consistent directions of associations for interaction effects with those in IOWBC (table 3)

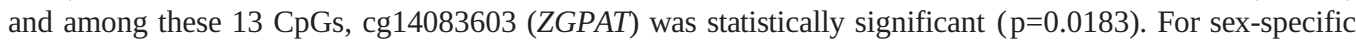
analysis in model-2, in males higher DNA-M at eight CpGs at early ages was associated with lower lung function at later ages, while in females higher DNA-M at those CpGs was associated with higher lung function. At the remaining five CpGs, higher DNA-M was associated with higher lung function in males, while in females it was associated with lower lung function (table 3).

\section{Results of gene expression analysis}

In a longitudinal assessment of DNA-M at age 18 years with gene expression at 26 years (36 males and 72 females), five identified CpGs in model-1 and 11 in model-2 had the corresponding gene expression data. In longitudinal assessment none of the five CpGs in model-1 were associated with the relevant gene expression. In model-2, amongst the 11 CpGs, DNA-M at cg01376079 (SSH3), cg07557690 (TGFBR3), and cg15981851 (AGAP1) at age 18 years showed significant association with gene expression at age 26 years (table 4). In cross-sectional association of DNA-M at age 26 years with gene expression at 26 years (54 males and 85 females), one CpG in model-1 had corresponding gene expression data but showed no association. In model-2, eight identified CpGs had gene expression data and DNA-M at three CpGs, cg01376079 (SSH3), cg07557690 (TGFBR3), and cg19736286 (MSH6), were shown to be cross-sectionally associated with gene expression, with cg01376079 and cg07557690 also being associated with expression of the corresponding gene in the longitudinal assessment. In both longitudinal and cross-sectional assessment, consistent directions of DNA-M and gene expression associations were found for cg01376079 and cg07557690; higher methylation at cg01376079 was associated with lower expression of SSH3, while higher methylation at cg07557690 was associated with higher expression of TGFBR3 (table 4).

\section{Results of the DMRs analysis}

DMR analyses focused on detecting regions showing differential methylation associated with lung function parameters. To potentially improve the power, via ttScreening, in males 486, 518, and $461 \mathrm{CpGs}$ and in females 419, 559, and 842 CpGs were selected based on their association with FVC, FEV 1 , and $\mathrm{FEV}_{1} / \mathrm{FVC}$, respectively, and were included in the DMR analyses. Using repeated measures of DNA-M and lung function, 17, 24, and 16 statistically significant DMRs in males and 57, 66, and 47 DMRs in females were identified for FVC, $\mathrm{FEV}_{1}$, and $\mathrm{FEV}_{1} / \mathrm{FVC}$, respectively $\left(\mathrm{p}_{F D R}<0.05\right)$. The DMRs containing $\geqslant 2$ CpGs are presented in table 5 and the complete results in table S3. In total, 132 and 382 CpGs were in the 57 and 170 identified DMRs in males and females, respectively. Four genes were common between the mapped genes of the individually identified CpGs and those of DMRs, namely TGFBR3, WNT10A, LY6H, and GMIP.

\section{Discussion}

We examined the longitudinal association of genome-wide DNA-M at ages 10 and 18 years with lung function at 18 and 26 years, respectively, using repeated measures from pre-adolescence to post-adolescence 
TABLE 3 DNA methylation at cytosine-phosphate-guanine dinucleotide sites (CpGs) at earlier age that showed consistent sex-specific association with lung function at later age between the Isle of Wight birth cohort (IOWBC) and the Avon Longitudinal Study of Parents and Children (ALSPAC)

\begin{tabular}{|c|c|c|c|c|c|c|c|c|c|c|}
\hline \multirow{2}{*}{$\begin{array}{l}\text { Lung function } \\
\text { measure }\end{array}$} & \multirow[t]{2}{*}{ CpGs } & \multirow[t]{2}{*}{ Sex } & \multirow{2}{*}{$\begin{array}{c}\text { Chromosome } \\
\text { number }\end{array}$} & \multirow{2}{*}{$\begin{array}{l}\text { Gene } \\
\text { name }\end{array}$} & \multirow[t]{2}{*}{ Location ${ }^{\#}$} & \multicolumn{3}{|c|}{ IOWBC } & \multicolumn{2}{|c|}{ ALSPAC } \\
\hline & & & & & & Coefficient & $\mathrm{p}_{\text {RAW }}$ & $\mathrm{p}_{F D R}$ & Coefficient & $\mathrm{p}$-value \\
\hline \multicolumn{11}{|l|}{ FVC } \\
\hline & cg01376079 & & 11 & SSH3 & TSS1500 & 0.09 & 0.38 & & 0.22 & 0.49 \\
\hline & cg01376079×sex & Male & & & & -0.41 & 0.0019 & 0.042 & -0.71 & 0.12 \\
\hline & $\operatorname{cg} 07230380$ & & 10 & $S C D$ & TSS1500 & -0.02 & 0.25 & & -4.77 & 0.62 \\
\hline & cg07230380×sex & Male & & & & 0.05 & 0.0012 & 0.042 & 16.21 & 0.23 \\
\hline & cg07557690 & & 1 & TGFBR3 & TSS1500 & 0.30 & 0.0014 & & 0.21 & 0.56 \\
\hline & cg07557690×sex & Male & & & & -0.41 & 0.0017 & 0.042 & -0.40 & 0.46 \\
\hline & $\operatorname{cg} 14083603$ & & 20 & ZGPAT & Body & -0.49 & $<0.0001$ & & -0.55 & 0.76 \\
\hline & cg14083603×sex & Male & & & & 0.69 & 0.0007 & 0.042 & 6.22 & 0.018 \\
\hline & cg23026420 & & 11 & $P P P 2 R 1 B$ & TSS200 & 0.17 & 0.0059 & & 2.96 & 0.66 \\
\hline & cg23026420×sex & Male & & & & -0.29 & 0.0019 & 0.041 & -11.86 & 0.19 \\
\hline \multicolumn{11}{|l|}{$\mathrm{FEV}_{1}$} \\
\hline & cg15981851 & & 2 & $A G A P 1$ & Body & 0.07 & 0.27 & & 0.10 & 0.77 \\
\hline & cg15981851×sex & Male & & & & -0.36 & 0.0002 & 0.015 & -0.057 & 0.91 \\
\hline & $\operatorname{cg} 16582803$ & & 2 & WNT10A & Intergenic & -0.09 & 0.77 & & -0.48 & 0.21 \\
\hline & cg16582803×sex & Male & & & & -0.29 & 0.0009 & 0.032 & -0.23 & 0.67 \\
\hline & cg19736286 & & 2 & MSH6 & TSS200 & 0.09 & 0.41 & & 0.23 & 0.90 \\
\hline & cg19736286×sex & Male & & & & -0.56 & 0.0011 & 0.032 & -1.36 & 0.59 \\
\hline \multicolumn{11}{|l|}{$\mathrm{FEV}_{1} / \mathrm{FVC}$} \\
\hline & cg02397934 & & 6 & $\mathrm{H} 2 \mathrm{BC} 13$ & Intergenic & -0.01 & 0.035 & & -0.094 & 0.46 \\
\hline & cg02397934×sex & Male & & & & 0.03 & 0.0004 & 0.024 & 0.21 & 0.25 \\
\hline & cg08650125 & & 8 & $L Y G H$ & Intergenic & 0.04 & 0.0014 & & 0.01 & 0.73 \\
\hline & cg08650125×sex & Male & & & & -0.06 & 0.0005 & 0.0236 & -0.029 & 0.50 \\
\hline & cg09059988 & & 1 & HORMAD1 & $\begin{array}{c}1^{\text {st }} \text { Exon; } \\
5^{\prime} \text { UTR }\end{array}$ & 0.01 & 0.36 & & -0.012 & 0.89 \\
\hline & cg09059988×sex & Male & & & & -0.06 & 0.0008 & 0.025 & -0.03 & 0.79 \\
\hline & cg20038169 & & 19 & GMIP & $\begin{array}{c}1^{\text {st }} \text { Exon; } \\
5^{\prime} \text { UTR }\end{array}$ & -0.02 & $<0.0001$ & & -0.59 & 0.66 \\
\hline & cg20038169×sex & Male & & & & 0.02 & 0.0007 & 0.025 & 1.823 & 0.34 \\
\hline & cg23370466 & & 5 & TRIM41 & Intergenic & -0.02 & 0.0045 & & -0.032 & 0.43 \\
\hline & cg23370466×sex & Male & & & & 0.04 & 0.0002 & 0.024 & 0.040 & 0.49 \\
\hline
\end{tabular}

Coefficients of IOWBC-ALSPAC consistent CpGs for the sex-specific association of DNA methylation at earlier age with lung function at a later age. The CpGs showed the same direction of associations and were significant at 0.05 level are shown in bold font. FEV $\mathrm{V}_{1}$ : forced expiratory volume in $1 \mathrm{~s}$; FVC: forced vital capacity; $\mathrm{p}_{F D R}$ : $\mathrm{p}$-value after multiple testing correction by controlling false discovery rate; $\mathrm{p}_{\text {RAW: }} \mathrm{p}$-value without multiple testing adjustment; $5^{\prime}$ UTR: $5^{\prime}$ untranslated region. \#: genes located at intergenic locations were not found in the Illumina annotation file and were identified using the online tool SNIPPER.

period at both individual sites and genomic regions. DNA-M at eight CpGs and $13 \mathrm{CpGs}$ at an earlier age was shown to be associated with lung function at a later age for main effects and sex-specific effects, respectively, in the IOWBC, with consistent findings in ALSPAC. Among IOWBC-ALSPAC consistent CpGs, cg16582803 (WNT10A) and cg14083603 (ZGPAT) were replicated in ALSPAC in terms of direction of associations and were statistical significance for main effect and interaction effects on lung function, respectively. DNA-M at cg01376079 (SSH3) and cg07557690 (TGFBR3) was associated with gene expression and invariant to longitudinal or cross-sectional assessment. In total, 57 and 170 DMRs at earlier age in relation to lung function at later age were identified in males and females, respectively.

In our study, at a certain proportion of CpGs, the longitudinal associations were shown to be sex-specific. One possible explanation for such an observation might be due to sex-specific changes of DNA-M over time as we have previously observed [20]. Other studies also suggested significant sex differences in patterns of blood-based DNA-M at the genome scale [31]. Although the current study focused on longitudinal association of DNA-M and lung function, the observation on sex-specificity is consistent with our previous findings [23, 32]. In previous studies, the associations of changes in DNA-M with lung function changes [23] and DNA-M with lung function trajectories were found to be different between males and females [32]. Our further analyses indicated that such sex-specificity was time-invariant. 


\section{TABLE 4 Association of DNA methylation (DNA-M) with gene expression in the Isle of Wight birth cohort (IOWBC)}

CpGs Chromosome number Gene name Location DNA-M at age 18 years with gene expression at 26 years
DNA-M at age 26 years with gene expression at 26 years

\begin{tabular}{|c|c|c|c|c|c|c|c|}
\hline \multicolumn{8}{|c|}{ Model 1: CpGs identified for main effects } \\
\hline \multicolumn{8}{|l|}{$\mathrm{FEV}_{1}$} \\
\hline cg10729557 & 14 & ANKRD9 & Intergenic & 0.10 & 0.73 & -0.053 & 0.77 \\
\hline $\operatorname{cg} 17315331$ & 11 & HINFP & TSS200 & 0.043 & 0.10 & & \\
\hline \multicolumn{8}{|l|}{$\mathrm{FEV}_{1} / \mathrm{FVC}$} \\
\hline $\operatorname{cg} 18760835$ & 6 & NRN1 & Intergenic & -0.072 & 0.21 & & \\
\hline $\operatorname{cg} 21240861$ & 7 & DNAJB6 & TSS200 & -0.01 & 0.62 & & \\
\hline $\operatorname{cg} 27601198$ & 16 & C16orf87 & Intergenic & 0.021 & 0.77 & & \\
\hline \multicolumn{8}{|c|}{ Model 2: CpGs identified for interactions effects } \\
\hline \multicolumn{8}{|l|}{ FVC } \\
\hline $\operatorname{cg} 01376079$ & 11 & SSH3 & TSS1500 & -0.17 & 0.011 & -0.17 & 0.0033 \\
\hline $\operatorname{cg} 07230380$ & 10 & $S C D$ & TSS1500 & -0.004 & 0.88 & & \\
\hline cg07557690 & 1 & TGFBR3 & TSS1500 & 1.07 & $2.0 \times 10^{-4}$ & 0.10 & $2.7 \times 10^{-7}$ \\
\hline cg14083603 & 20 & ZGPAT & Body & -0.058 & 0.69 & 0.18 & 0.20 \\
\hline cg23026420 & 11 & PPP2R1B & TSS200 & 0.001 & 0.99 & 0.081 & 0.36 \\
\hline \multicolumn{8}{|l|}{$\mathrm{FEV}_{1}$} \\
\hline $\operatorname{cg} 15981851$ & 2 & $A G A P 1$ & Body & -0.63 & 0.028 & -0.23 & 0.29 \\
\hline $\operatorname{cg} 16582803$ & 2 & WNT10A & Intergenic & -0.20 & 0.31 & & \\
\hline cg19736286 & 2 & MSH6 & TSS200 & -0.12 & 0.58 & -0.38 & 0.0165 \\
\hline \multicolumn{8}{|l|}{$\mathrm{FEV}_{1} / \mathrm{FVC}$} \\
\hline cg09059988 & 1 & HORMAD1 & $1^{\text {st }}$ Exon; $5^{\prime}$ UTR & -0.16 & 0.62 & 0.18 & 0.52 \\
\hline cg20038169 & 19 & GMIP & $1^{\text {st }}$ Exon; $5^{\prime}$ UTR & 0.021 & 0.38 & & \\
\hline cg23370466 & 5 & TRIM41 & Intergenic & 0.011 & 0.84 & -0.028 & 0.52 \\
\hline
\end{tabular}

The mapped genes of replicated CpGs, such as cg16582803 on WNT10A and cg14083603 on ZGPAT, have plausible biological relevance to lung function and respiratory diseases. The Wnt/ $\beta$-catenin pathway is centrally involved in lung development and several lung diseases [33, 34]. In particular, WNT10A plays an important role in pathogenesis of idiopathic pulmonary fibrosis (IPF) via transforming growth factor (TGF)- $\beta$ activation [34]. Genetic variation in ZGPAT has been shown to be associated with lung function and also the risk of asthma and atopic dermatitis [35-37]. It has been suggested that DNA-M in ZGPAT has a causal effect on $\mathrm{FEV}_{1}$, mediated by changes in the expression of ZGPAT [37].

Longitudinal association of DNA-M at CpGs/DMRs with lung function measures at a later age may provide insight into the pathogenesis of impaired lung function growth. The association of differential methylation at some of these CpGs with gene expression, such as cg15981851 (AGAP1) for time-lagged, cg19736286 (MSH6) for cross-sectional assessment, and cg01376079 (SSH3) and cg07557690 (TGFBR3) for both longitudinal and cross-sectional assessment suggests a functional relevance of these CpGs. cg01376079 (SSH3) and cg07557690 (TGFBR3) manifest stable effects of DNA-M on gene expression. All the CpGs associated with the gene expression are located at promoter regions, except for cg15981851 (AGAP1), which is in the gene body (table 4).

It is important to note the biological relevance of cg07557690, located in the promoter region of gene TGFBR3 (TGF- $\beta$ receptor type III). Among the identified CpGs showing associations with gene expression, the association of cg07557690 with expression of TGFBR3 was the strongest in both effect size and statistical significance. Expression of TGFBR3 is essential for optimal TGF-signalling during embryonic lung development [38]. TGF- $\beta$ is also a key regulator of extracellular matrix composition and alveolar epithelial cell and fibroblast function in the lung. Prolonged alterations of TGF- $\beta$ and its receptors result in compromised gas exchange and lung function, a feature of bronchopulmonary dysplasia, lung fibrosis and COPD $[38,39]$. In addition, TGFBR3 has been suggested to play key roles in the pathogenesis of asthma [40] and COPD susceptibility [39]. TGFBR3 is also mapped within two lung function associated 
TABLE 5 Differentially methylated regions (DMRs; containing $\geqslant 2$ cytosine-phosphate-guanine dinucleotide sites (CpGs)) of lung function at later age in relation to DNA methylation at earlier age identified by the DMRcate method

Molecular location of DMR

CpGs n

Stouffer

Annotated gene

(chromosome: start - end)

\begin{tabular}{|c|c|c|c|}
\hline \multicolumn{4}{|l|}{ Male } \\
\hline \multicolumn{4}{|l|}{ FVC } \\
\hline chr4: 2819770-2820479 & 4 & 0 & $\mathrm{SH} 3 \mathrm{BP} 2$ \\
\hline chr8: $11659832-11660733$ & 3 & 0 & FDFT1, RP11 \\
\hline chr3: 194014481-194014745 & 3 & $1.30 \times 10^{-198}$ & CPN2 \\
\hline \multicolumn{4}{|l|}{$\mathrm{FEV}_{1}$} \\
\hline chr4: $1004525-1004678$ & 3 & 0 & FGFRL1 \\
\hline chr6: $33084825-33085031$ & 3 & 0 & $H L A-D P B 2^{\#}$ \\
\hline chr15: 30163660-30163825 & 3 & $2.00 \times 10^{-203}$ & $T J P 1^{\#}$ \\
\hline chr6: $2891973-2892150$ & 3 & $9.07 \times 10^{-66}$ & SERPINB9 ${ }^{\#}$ \\
\hline \multicolumn{4}{|l|}{$\mathrm{FEV}_{1} / \mathrm{FVC}$} \\
\hline chr6: $30038929-30039435$ & 10 & 0 & RNF39 ${ }^{\#}$ \\
\hline chr19: 1467008-1467032 & 3 & 0 & $A P C 2^{\#}$ \\
\hline chr6: $33871907-33872861$ & 3 & $4.70 \times 10^{-188}$ & MIR1275 \\
\hline \multicolumn{4}{|l|}{ Female } \\
\hline \multicolumn{4}{|l|}{ FVC } \\
\hline chr22: 30476089-30476525 & 5 & $7.80 \times 10^{-280}$ & HORMAD2, CTA \\
\hline chr6: 88757302-88757392 & 5 & $7.46 \times 10^{-74}$ & SPACA1 \\
\hline chr1: 92352293-92352481 & 3 & 0 & TGFBR3 \\
\hline chr10: $135191624-135192230$ & 3 & 0 & PAOX, AL360181.1-201 \\
\hline chr11: 2322500-2322808 & 3 & 0 & TSPAN32, C11orf21 \\
\hline chr20: 25677290-25677582 & 3 & 0 & ZNF337 \\
\hline chr5: 112824497-112824765 & 3 & $7.90 \times 10^{-254}$ & MCC \\
\hline chr17: 56744332-56744490 & 3 & $9.80 \times 10^{-216}$ & RNU1 \\
\hline chr10: 34408530-34408654 & 3 & $3.50 \times 10^{-139}$ & PARD $^{\#}$ \\
\hline chr15: 99975310-99975470 & 3 & $1.30 \times 10^{-107}$ & $\operatorname{LRRC28^{\# }}$ \\
\hline \multicolumn{4}{|l|}{$\mathrm{FEV}_{1}$} \\
\hline chr5: 1867978-1868693 & 5 & $2.75 \times 10^{-84}$ & $I R X 4^{\#}$ \\
\hline chr17: 45949743-45949878 & 4 & 0 & $S P 6^{\#}$ \\
\hline chr6: 32016257-32017229 & 4 & 0 & $T N X B$ \\
\hline chr22: 30476089-30476525 & 4 & $6.50 \times 10^{-182}$ & HORMAD2, CTA \\
\hline chr11: 18433554-18433745 & 4 & $5.93 \times 10^{-39}$ & LDHC \\
\hline chr6: 110720918-110721349 & 4 & $8.70 \times 10^{-26}$ & $D D O^{\#}$ \\
\hline chr7: 157512397-157513707 & 3 & 0 & PTPRN2 ${ }^{\#}$ \\
\hline chr7: 150037890-150038898 & 3 & $3.60 \times 10^{-219}$ & RARRES2 \\
\hline chr6: 32294470-32294577 & 3 & $1.30 \times 10^{-190}$ & HNRNPA1P2 \\
\hline chr20: 62328084-62328427 & 3 & $7.10 \times 10^{-181}$ & TNFRSF6B \\
\hline chr10: $34408530-34408654$ & 3 & $2.30 \times 10^{-139}$ & PARD3 ${ }^{\#}$ \\
\hline chr15: 99975310-99975470 & 3 & $4.30 \times 10^{-108}$ & $L R R C 28^{\#}$ \\
\hline chr8: $37605517-37605783$ & 3 & $6.66 \times 10^{-95}$ & RP11-109A6.3 \\
\hline chr17: 154420-154671 & 3 & $1.37 \times 10^{-88}$ & RPH3AL \\
\hline \multicolumn{4}{|l|}{$\mathrm{FEV}_{1} / \mathrm{FVC}$} \\
\hline chr1: 2058230-2059086 & 3 & 0 & $P R K C Z^{\#}$ \\
\hline chr17: 40936570-40937362 & 3 & 0 & WNK4 \\
\hline chr20: 44829602-44829821 & 3 & 0 & $\mathrm{CDH} 22^{\#}$ \\
\hline chr2: 113993052-113994035 & 3 & $3.10 \times 10^{-156}$ & PAX8-AS1 \\
\hline chr7: 57471759-57472367 & 3 & $1.80 \times 10^{-131}$ & MIR3147 \\
\hline chr1: 43814764-43815035 & 3 & $2.22 \times 10^{-21}$ & MPL \\
\hline
\end{tabular}

DMRcate annotates to UCSC RefGene from the Illumina annotation file. FEV ${ }_{1}$ : forced expiratory volume in $1 \mathrm{~s}$; FVC: forced vital capacity. ": genes were not found in the Illumina annotation file and were identified using the online tool SNIPPER.

DMRs in this study. Together these results suggest that cg07557690 has potential utility as a biomarker of lung function development. Future in-depth studies of cg07557690 and how it is related to lung function are warranted. 
An important strength of this study is its longitudinal design in which DNA-M measurement always precedes the lung function measurement to avoid temporal ambiguity (reverse causation). With repeated measures, longitudinally designed studies potentially gain a higher power to detect change over time and to identify differences between individuals, compared with cross-sectional studies. Moreover, the inclusion of a validation cohort increased the testing power of the identified CpGs. In addition, CpGs showing agreement between the two cohorts have potential generalisability at least in Caucasians.

There are a few limitations to this study. The median value of $\mathrm{FEV}_{1}$ at age 18 years, the proportion of males and females at age 18 years and smoking status at 26 years were different in the analysed samples to the overall study cohort. At age 26 years, lung function was available for fewer participants compared with age 18 years, leading to a smaller sample size in period-2. This study has Caucasian participants in both cohorts. Although we believe using a replication cohort with the same ethnicity as in the discovery cohort potentially improved the testing power, this design may limit the generalisability of the findings to other populations. In addition, while methylation of several CpGs was shown to be associated with relevant gene expression, this was in mixed cell populations from whole blood and it is not possible to assess cell-type specificity of the relationship, or the relevance to gene expression in the lung. Nevertheless, the identified CpGs have the potential to serve as candidate CpGs for lung function impairment prediction in future studies. Screening for such CpGs in early life may help to identify children at higher risk of reduced lung function at later ages.

Acknowledgements: The authors gratefully acknowledge the cooperation of the children and parents who participated in this study and appreciate the hard work of the Isle of Wight research team in collecting data. We thank the High-Throughput Genomics Group at the Wellcome Trust Centre for Human Genetics (funded by Wellcome Trust grant ref. 090532/Z/09/Z and MRC Hub grant G0900747 91070) for the generation of the methylation data. The authors are thankful to the High-Performance Computing facility at the University of Memphis. For the ALSPAC cohort, we are extremely grateful to all the families who took part in this study, the midwives for their help in recruiting them, and the whole ALSPAC team, which includes interviewers, computer and laboratory technicians, clerical workers, research scientists, volunteers, managers, receptionists, and nurses.

Author contributions: S.K. Sunny carried out the study, conducted all the statistical analysis, interpreted the data and drafted the manuscript. H. Zhang designed the study, guided the analysis, and was involved in drafting and revision of the manuscript. F. Mzayek contributed to the conception and critical revision of the manuscript. J.W. Holloway and S. Ewart supervised the DNA methylation and RNA-seq measurement in IOWBC, and revised the manuscript. L. Kadalayil was involved in processing of RNA-seq data. S.H. Arsad was involved in data acquisition, DNA-M arraying and study design in IOWBC, and reviewed the manuscript. C.L. Relton and S. Ring were involved in the ALSPAC study design and provided the data. All authors read and approved the final manuscript.

Conflict of interest: S.K. Sunny has nothing to disclose. H. Zhang has nothing to disclose. C.L. Relton has nothing to disclose. S. Ring has nothing to disclose. L. Kadalayil has nothing to disclose. F. Mzayek has nothing to disclose. S. Ewart has nothing to disclose. J.W. Holloway reports grants from the National Institutes of Health (USA) during the conduct of the study. S.H. Arshad has nothing to disclose.

Support statement: The study conveyed in this publication was supported by the National Institute of Allergy and Infectious Diseases under Award Number R01 Al121226 (MPI: H. Zhang and J.W. Holloway). The 10-year follow-up of IOW cohort was funded by National Asthma Campaign, UK (grant number 364) and the 18-year follow-up by a grant from the National Heart and Blood Institute (R01 HL082925; principal investigator: S.H. Arshad). The UK Medical Research Council (MRC) and Wellcome (grant ref. 102215/2/13/2), and the University of Bristol provide core support for ALSPAC. A comprehensive list of grants funding is available on the ALSPAC website (www.bristol.ac.uk/ alspac/external/documents/grant-acknowledgements.pdf). Generation of methylation array data was specifically funded by NIH R01Al121226 and R01AI091905, BBSRC BBI025751/1 and BB/1025263/1, and MRC MC_UU_12013/1, MC_UU_12013/2 and MC_UU_12013/8. Lung function measurements and were funded by grants from the MRC (G0401540/73080 and MR/M022501/1). Funding information for this article has been deposited with the Crossref Funder Registry.

References

$1 \quad$ Postma DS, Bush A, van den Berge M. Risk factors and early origins of chronic obstructive pulmonary disease. Lancet 2015; 385: 899-909.

2 Vasquez MM, Zhou M, Hu C, et al. Low lung function in young adult life is associated with early mortality. Am J Respir Crit Care Med 2017; 195: 1399-1401. 
3 Kohansal R, Martinez-Camblor P, Agustí A, et al. The natural history of chronic airflow obstruction revisited: an analysis of the Framingham Offspring Cohort. Am J Respir Crit Care Med 2009; 180: 3-10.

4 Knudson RJ, Lebowitz MD, Holberg $\mathrm{CJ}$, et al. Changes in the normal maximal expiratory flow-volume curve with growth and aging. Am Rev Respir Dis 1983; 127: 725-734.

5 LoMauro A, Aliverti A. Sex differences in respiratory function. Breathe 2018; 14: 131-140.

6 Becklake MR, Kauffmann F. Gender differences in airway behaviour over the human life span. Thorax 1999; 54: 1119-1138.

7 Schultz ES, Gruzieva O, Bellander T, et al. Traffic-related air pollution and lung function in children at 8 years of age: a birth cohort study. Am J Respir Crit Care Med 2012; 186: 1286-1291.

8 Maher B. Personal genomes: the case of the missing heritability. Nature 2008; 456: 18-21.

9 de Jong K, Vonk JM, Timens W, et al. Genome-wide interaction study of gene-by-occupational exposure and effects on FEV1 levels. J Allergy Clin Immunol 2015; 136: 1664-1672.

10 van der Plaat DA, de Jong $\mathrm{K}$, de Vries $\mathrm{M}$, et al. Occupational exposure to pesticides is associated with differential DNA methylation. Occup Environ Med 2018; 75: 427-435.

11 Moore LD, Le T, Fan G. DNA methylation and its basic function. Neuropsychopharmacology 2013; 38: 23-38.

12 Qiu W, Baccarelli A, Carey VJ, et al. Variable DNA methylation is associated with chronic obstructive pulmonary disease and lung function. Am J Respir Crit Care Med 2012; 185: 373-381.

13 Lepeule J, Baccarelli A, Motta V, et al. Gene promoter methylation is associated with lung function in the elderly: the Normative Aging Study. Epigenetics 2012; 7: 261-269.

14 Busch R, Qiu W, Lasky-Su J, et al. Differential DNA methylation marks and gene comethylation of COPD in African-Americans with COPD exacerbations. Respir Res 2016; 17: 143.

15 Lee MK, Hong Y, Kim SY, et al. Epigenome-wide association study of chronic obstructive pulmonary disease and lung function in Koreans. Epigenomics 2017; 9: 971-984.

16 Lange NE, Sordillo J, Tarantini L, et al. Alu and LINE-1 methylation and lung function in the normative ageing study. BMJ Open 2012; 2: e001231.

17 Imboden M, Wielscher M, Rezwan Fl, et al. Epigenome-wide association study of lung function level and its change. Eur Respir J 2019; 54: 1900457.

18 Zhang $\mathrm{H}$, Tong X, Holloway JW, et al. The interplay of DNA methylation over time with Th2 pathway genetic variants on asthma risk and temporal asthma transition. Clin Epigenet 2014; 6: 8.

19 Florath I, Butterbach K, Muller H, et al. Cross-sectional and longitudinal changes in DNA methylation with age: an epigenome-wide analysis revealing over 60 novel age-associated CpG sites. Hum Mol Genet 2014; 23: $1186-1201$.

20 Han L, Zhang H, Kaushal A, et al. Changes in DNA methylation from pre- to post-adolescence are associated with pubertal exposures. Clin Epigenetics 2019; 11: 176.

21 Mulder RH, Neumann A, Cecil CAM, et al. Epigenome-wide change and variation in DNA methylation in childhood: trajectories from birth to late adolescence. Hum Mol Genet 2021; 30: 119-134.

22 Patil VK, Holloway JW, Zhang $\mathrm{H}$, et al. Interaction of prenatal maternal smoking, interleukin 13 genetic variants and DNA methylation influencing airflow and airway reactivity. Clin Epigenetics 2013; 5: 22.

23 Sunny SK, Zhang $\mathrm{H}$, Rezwan FI, et al. Changes of DNA methylation are associated with changes in lung function during adolescence. Respir Res 2020; 21: 80.

24 Pal S, Tyler JK. Epigenetics and aging. Sci Adv 2016; 2: e1600584.

25 Boyd A, Golding J, Macleod J, et al. Cohort Profile: the 'children of the 90s'--the index offspring of the Avon Longitudinal Study of Parents and Children. Int J Epidemiol 2013; 42: 111-127.

26 Fraser A, Macdonald-Wallis C, Tilling K, et al. Cohort profile: the Avon Longitudinal Study of Parents and Children: ALSPAC mothers cohort. Int J Epidemiol 2013; 42: 97-110.

27 Li X, Hawkins GA, Ampleford EJ, et al. Genome-wide association study identifies TH1 pathway genes associated with lung function in asthmatic patients. J Allergy Clin Immunol 2013; 132: 313-320.

28 Ray MA, Tong X, Lockett GA, et al. An efficient approach to screening epigenome-wide data. Biomed Res Int 2016; 2016: 2615348.

29 Benjamini $Y$, Hochberg Y. Controlling the false discovery rate: a practical and powerful approach to multiple testing. J R Stat Soc Series B 1995; 57: 289-300.

30 Peters TJ, Buckley MJ, Statham AL, et al. De novo identification of differentially methylated regions in the human genome. Epigenetics Chromatin 2015; 8: 6.

31 Singmann P, Shem-Tov D, Wahl S, et al. Characterization of whole-genome autosomal differences of DNA methylation between men and women. Epigenetics Chromatin 2015; 8: 43.

32 Sunny SK, Zhang H, Mzayek F, et al. Pre-adolescence DNA methylation is associated with lung function trajectories from pre-adolescence to adulthood. Clin Epigenetics 2021; 13: 5.

33 Weng T, Liu L. The role of pleiotrophin and $\beta$-catenin in fetal lung development. Respir Res 2010; 11: 80.

34 Oda K, Yatera K, Izumi $\mathrm{H}$, et al. Profibrotic role of WNT10A via TGF- $\beta$ signaling in idiopathic pulmonary fibrosis. Respir Res 2016; 17: 39. 
35 Sun L-D, Xiao F-L, Li Y, et al. Genome-wide association study identifies two new susceptibility loci for atopic dermatitis in the Chinese Han population. Nat Genet 2011; 43: 690-694.

36 Wain LV, Shrine N, Artigas MS, et al. Genome-wide association analyses for lung function and chronic obstructive pulmonary disease identify new loci and potential druggable targets. Nat Genet 2017; 49: 416.

37 Jamieson E, Korologou-Linden R, Wootton RE, et al. Smoking, DNA methylation, and lung function: a mendelian randomization analysis to investigate causal pathways. Am J Hum Genet 2020; 106: 315-326.

38 Pozarska A, Niess G, Seeger W, et al. A role for the accessory type III transforming growth factor $\beta$ receptor (Tgfbr3) in lung alveolarisation. Eur Respir J 2016; 48: Suppl. 60, PA4026.

39 Morty RE, Königshoff M, Eickelberg O. Transforming growth factor- $\beta$ signaling across ages: from distorted lung development to chronic obstructive pulmonary disease. Proc Am Thorac Soc 2009; 6: 607-613.

$40 \mathrm{Kim} \mathrm{H}-\mathrm{K}$, Jang T-W, Jung M-H, et al. Association between genetic variations of the transforming growth factor $\beta$ receptor type III and asthma in a Korean population. Exp Mol Med 2010; 42: 420-427. 